$M^{\mathrm{a}}$ Jesús Martín Sastre

Universidad Autónoma de Madrid

\title{
EL ASPECTO RELIGIOSO EN LA CELESTINA
}

Mucho se ha escrito sobre el aspecto religioso en La Celestina. Unos no ven en la obra rastro religioso alguno (Américo Castro, Julio Rodríguez Puértolas, Ma Rosa Lida, Stephen Gilman...); otros, por el contrario, quieren ver en la obra un propósito moral y religioso. Hay quienes defienden que la religión que impregna la obra es la cristiana (Menéndez Pelayo, M. Bataillon, $\mathrm{O}$. $\mathrm{H}$. Green, G. Correa, Morón Arroyo, S. Baldwin, C. Ripoll, J. A. Maravall...). Y quienes creen que lo que se expresa en la obra es el judaísmo original de su autor (O. Martínez-Miller, Ramiro de Maeztu, Serrano Poncela, A. M. Forcadas).

A mi parecer, en La Celestina todo se derrumba y destruye: la sociedad y la cultura en la que el texto está asentado; el mundo en el que vive el autor, y, por supuesto, también la religión. Por ello en la obra no hay sentimiento religioso alguno (ni cristiano ni judaico). Todo se convierte en una sátira destructiva y letal.

Fernando de Rojas es un judio converso, ha vivido el peligro de los conversos y ha conocido la cultura milenaria judia, pero también la cristiana. Formalmente hay más elementos cristianos en la obra, ahi estaba la Inquisición, no puede haber muchos elementos judios explicitos. Pero, por otra parte, tampoco hay ninguna referencia a Cristo. Notamos ausencias espectaculares del mundo cristiano, tanto como del universo cultural judio. Rojas juega con todo, pero ni cristianismo ni judaísmo poseen un papel relevante en La Celestina.

Hay tres referencias estratégicas en las que se une a las tres religiones peninsulares de la época: Sempronio trata de hacer ver a Calisto que las mujeres no merecen la pena, y une a las tres religiones en un nivel de igualdad antifeminista: "gentiles, judios, cristianos y moros, todos en esta concordia están" (I.2). Celestina recuerda a Pármeno que su madre era una bruja y que desenterraba a los muertos para usarlos en sus prácticas brujeriles e infernales. Judios, musulmanes y cristianos son iguales ante la muerte y ante las prácticas de brujeria: "Ni dexava cristianos ni moros ni judíos cuyos enterramientos no visitava. De dia los acechava, de noche los desenterrava" (VII.1). En el Monólogo de Pleberio las tres razas aparecen igualadas ante la muerte, ante el fuego (del amor o de la Inquisición); ante la destrucción: "Tu fuego es de ardiente rayo, que jamás haze señal do llega. La leña que gasta tu llama son almas y vidas de humanas criaturas, las quales son tantas que de quien començar apenas me ocurre. No sólo de cristianos, mas de gentiles y judios. Y todo en pago de buenos servicios" (XXI).

Por otra parte, si bien es cierto que hay rastros judios -algunos criticos, como Serrano Poncela, Orozco Díaz y Garrido Pallardó explican el suicidio de Melibea como una característica hebrea-, hay también rastros de un cierto antisemitismo. "Los falsos judios su haz escupieron, I vinagre con hiel fue su potación [...]" (Piezas finales).

Además, podrían realizarse lecturas ateas de la obra, por ejemplo del prólogo filosófico. En él, aparece la Naturaleza como la madre de todas las cosas. El mundo habría sido creado por ella, y 
no por Dios (ya cristiano, ya judio): "Sin lid y offensión ninguna cosa engendró la Natura, madre de todo" (Prólogo).

Hay una completa ausencia de Dios también en el suicidio de Melibea. En el pensamiento cristiano no cabe la autodestrucción, pues sólo Dios es dueño de la vida. Sin embargo, ella parece feliz porque cree que al morir va a reencontrarse con Calisto, no piensa en su condenación. Él es lo único en lo que Melibea cree.

La ausencia de los elementos fundamentales del cristianismo es patente y significativo. Elicia decide vengarse contra Calisto y Melibea (XV.3) sin el menor remordimiento ni sentido del pecado. Lo mismo sucede con Areúsa por el mismo motivo: "Y de ál [otra cosa] me vengue Dios, que de Calisto Centurio me vengará" (XV.3). Dios es un ser vengador.

Ante el suicidio de su hija, tanto Pleberio como Alisa desean morir también:

Ali.- [A Pleberio] ¿Por qué pides la muerte? [...] ¿Es algún mal de Melibea?

Por Dios, que me lo digas, porque si ella pena, no quiero yo vivir. (XXI)

El deseo de morir, como hemos dicho, no es propio de la religión cristiana. En ella actúan la esperanza, la conftanza en Dios y la resignación.

En un análisis detallado de los elementos cristianos de La Celestina, podremos comprobar que lo que hay no es más que falsedad; una religión desviada. Aparecen textos bíblicos utilizados perversamente, parodias y sátiras religiosas, una utilización no ortodoxa de la religión (rezos interesados...); que también se la emplea para justificar acciones poco correctas. Aunque la obra está llena de sentimiento cultural cristiano, no lo está de cristianismo. Una de las citas biblícas es la que introduce Celestina al recordar a Claudina, la madre de Pármerno. Ésta fue una bruja y la Inquisición la persiguió. Pero Celestina dirá sobre esto:

[...] la Sancta Escritura tenía que bienaventurados eran los que padescían persecución por la justicia, y que aquellos poseerian el reyno de los cielos (VII.1).

Así fue perseguida la madre de Pármeno; pero por sus malos actos. Hay ironía, pues entonces todos los malos tendrian el reino de Dios, pues serán perseguidos por sus maldades. La cita, perversamente tomada por Celestina, pertenece a Mateo, 5.10.

En otro momento, Celestina trata de convencer a Pármeno para que no esté enemistado con Sempronio. Lo hace por propio interés; para que todos estén de su lado en el plan que tiene con respecto a los amores de Calisto por Melibea. Pármeno dice que va a hacer caso de lo que Celestina le aconseja porque: "La paz no se deve negar, que bienaventurados son los pacíficos, que fijos de Dios serán llamados" (I.10). Según lo que manda Dios, va a hacer caso a la alcahueta para aprovecharse de Calisto en nombre de Éste. La cita se encuentra en Mateo, 5.9.

Otro aspecto de esa religión desviada que aparece en La Celestina es su utilización no ortodoxa. Los rezos son interesados; si alguien se acuerda de Dios es para utilizarlo, si alguien va a la iglesia es para pedir cosas muy concretas. Dios y la iglesia están instrumentalizados. Los sentimientos espirituales no funcionan.

Las gentes van a visitar la iglesia de la Magdalena. En la Biblia, Magdalena la Penitente fue primero prostituta. Pasaría penalidades y acabó haciéndose santa. Es un juego irónico con elementos cristianos.

Celestina parece sacar fuerzas de la religión para ir a convencer a Melibea de que ame a Calisto: “iNo desmayes! Que nunca faltan rogadores para mitigar las penas” (IV.1). No ha de des- 
mayar en su intento (se dice a sí misma). Habrá gente que rece por ella; para que este daño se realice. Efectivamente, Calisto irá a rezar por este motivo en VIII.5.

Celestina pone como excusa de su visita a Melibea una oración que ésta sabe a Santa Apolonia, para llevársela a Calisto y que se le cure el dolor de muelas. De nuevo la religión es utilizada para otros fines. Se recurre a Dios por asuntos amorosos. Ir a la iglesia, rogar a Dios... está relacionado con problemas de amor.

Celestina crea un pecado relacionado con el egoísmo al dirigirse a Areúsa con estas palabras:

Por Dios, pecado ganas en no dar parte destas gracias a todos los que bien te quieren, que no te las dio Dios para que pasasen en balde por la frescor de tu juventud debaxo de seys dobles de paño y lienço (VII.2).

Es pecado no entregarse sexualmente a todos con un cuerpo tan hermoso como el suyo. Utiliza el concepto cristiano de pecado para dárselo justo a lo contrario de lo que sería éste.

La religión usada en su forma desviada también sirve para justificar acciones o para diluir la responsabilidad propia en la voluntad de Dios. Podemos comprobarlo en los siguientes ejemplos:

[...] cada dia hay hombres penados por mugeres y mugeres por hombres, y esto obra la natura, y la natura ordenóla Dios, y Dios no hizo cosa mala (IV.5).

En la religión cristiana Dios es el Creador. Celestina sería obra de Dios. Como Éste no ha hecho cosa mala, Celestina y sus acciones no serian tales; del mismo modo, el que hombres y mujeres penen no es cosa mala (que sí lo parecería). Todos los malos actos que va a realizar Celestina estarian justificados por Dios. Él está de acuerdo con sus actos; le placen, pues los permite.

Celestina va a casa de una Melibea ya enamorada de Calisto. Ésta le pide que la cure con su saber, a lo que Celestina le responde:

Señora, el sabidor sólo Dios es, pero como para salud y remedio de las enfermedades fueron repartidas las gracias en las gentes de hallar las melezinas, [...] alguna partezica alcançó a esta pobre vieja [...] (X.2).

Todo el saber de Celestina sobre alcahuetería le habria sido transmitido de Dios. Todas sus artes y sus mañas procederían de Él.

Celestina justifica su manera de actuar y su oficio por haber sido hecha así por Dios:

[...] soy una vieja qual Dios me hizo, no peor que todas. Vivo de mi oficio, como cada qual oficial del suyo, muy limpiamente. [...]. Si bien o mal vivo, Dios es el testigo de mi coraçón (XII.9).

Ni ella ni su oficio pueden ser malos, pues Dios la ha hecho asi: prostituta, bruja, alcahueta ...; y está en su corazón.

Una nueva forma de expresión de la religión desviada es la utilización paródica o irónica de la religión. Puede ser una ironía general con relación a Dios, como en:

Cel.- [A Calisto] Esfuérçate, señor, que no hizo Dios a quien desamparasse (VI).

Todos los personajes de la obra están desamparados. O no los ha hecho Dios (no creen en Él), o hay crítica contra Éste.

Centurio, a petición de Areúsa, va a matar a Calisto para vengar la muerte de los criados. Areúsa desea que Dios haga que el crimen salga bien: "Pues Dios te dé buena manderecha, y a él te encomiendo, [...]".

La ironía puede llegar de la mano de los personajes al expresar cosas contrarias a la realidad. Celestina, al tratar de convencer a Melibea de que acepte el amor de Calisto, le dirá : "Y verás cómo es todo más servicio de Dios que passos deshonestos" (IV.5). Pero en realidad es todo lo contrario. 
Centurio va a matar a Calisto para vengar a Areúsa y a Elicia. Va a cometer un crimen, pero se interesa por saber si aquél a quien va a asesinar está confesado:

Cen.- [...] Dime luego si está confessado.

Are.- No seas tú cura de su ánima.

Cen.- Pues sea assí. Enviémosle a comer al infierno sin confessión (XVIII.1).

A Centurio le acaba dando igual que Calisto esté confesado o no.

Cuando Celestina ve que Pármeno y Sempronio la van a matar exclama: “Ay, que me ha muerto! ¡Ay, ay! ¡Confessión, confessión!” (XII.10). Quizá Celestina no está pidiendo la confesión cristiana, y que esta frase sólo salga de su boca producida por el miedo. Ella era una mujer malvada, que invocaba al diablo...

Calisto, cuando cae del muro y va a morir, también pide confesión: “¡O, válame Santa Maria! ¡Muerto soy! ¡Confessión!” (XIX.8). La primera exclamación podría considerarse una fórmula de espanto, horror... La desesperación de verse morir le llevaría a gritar "confessión", habiendo quizá perdido la razón. Puede que esté pidiendo confesión sin estarse dando cuenta de lo que realmente está diciendo. Quizá sea una parodia religiosa: Calisto no tiene más Dios que a Melibea. Otis $\mathrm{H}$. Green (1969) cree que los pecadores mueren sin confesión y en pecado mortal. Sólo pueden hacerse estas afirmaciones leyendo desde una mentalidad cristiana. En la obra no está presente la idea de pecado en los personajes, por lo que ni morirán en pecado ni necesitarán de la confesión. Maravall (1964) considera que no tienen noción de pecado, pero afirma que a cada forma de actuar le corresponde un premio o un castigo. Como los personajes de la obra actúan mal, son castigados con la muerte.

Otro aspecto que se satiriza en la obra de Rojas es la relación del clero con la prostitución, a través de Celestina. Los trabajos de la vieja aparecen mezclados con expresiones religiosas. Pármeno, hablando con las muchachas que, al cargo de Celestina, se dedicaban a la prostitución dice:

[...] y aquestas, en tiempo onesto, como estaciones, processiones de noche, missas de gallo, missas del alva y otras secretas devociones, muchas encubiertas vi entrar en su casa [...] (I.5).

Los curas, cuando Celestina entraba en la iglesia, se quitaban el bonete, porque tenian relación con los trabajos de ésta, y:

[...] Allí se concertavan sus venidas a mi casa, allí las ydas a la suya, allí se me ofrecían dineros, allí promesas, alli otras dádivas, besando el cabo de mi manto [...] (IX.3).

Hay una fuerte crítica anticlerical. Los clérigos tenían relación con las prostitutas que Celestina tenía a su cargo, y adoraban a ésta porque se las proporcionaba. Menéndez Pelayo (1910: CXIIICXXXV), aunque se ha dado cuenta de la sátira anticlerical, ha leído la obra desde el punto de vista moralista, y la considera como un planteamiento de los males de la sociedad para intentar mejorarlos. Pero en la obra no hay ningún pensamiento optimista hacia el futuro.

Sempronio, refiriéndose al tipo de devociones que tiene Celestina, dirá:

[...] Lo que en sus cuentas reza es los virgos que tiene a cargo, y quántos enamorados hay en la cibdad, y quántas moças tiene encomendadas, [...] y qué canónigo es más moço y franco (IX.1).

Se parodian también elementos pertenecientes al cristianismo. Celestina va a casa de Melibea con el pretexto de buscar una oración que conoce ésta, y su cordón, para que a Calisto se le cure el dolor de muelas. Lo que es en realidad es una parodia de las reliquias de la Iglesia Católica. Se comparan los nudos del cordón de Melibea con los "nudos de la Pasión" (devoción cristiana de la 
época: rezar eso era como rezar un rosario a la muerte de Cristo) (VI). Es una parodia en la que se considera la pasión amorosa como equivalente a la religioisa.

Un personaje como Centurio es comparado por Elicia con un santo y con un ángel en XVIII.1. Pero Centurio es un salvaje, un asesino a sueldo..., y lo que tan angelical le ha parecido a Elicia ha sido otra cosa:

Mándame tú, señora, cosa que yo sepa hazer, cosa que sea de mi oficio. Un desafio con tres juntos y si más vinieren, que no huya por tu amor. Matar un hombre, cortar una pierna o braço [...] (XVIII.1).

Hay una innegable ironía religiosa. Un santo no hablaria de matar a un hombre...

Una nueva comparación paródica es la de la casa de Celestina con el Paraiso cuando Pármeno y Sempronio van allí en IX.2. El paraíso que podría ser la casa es el del vicio. Está convencida de que van a ir al Paraíso; pero quizá allí no quepa ninguno de ellos.

En La Celestina también está presente la parodia de expresiones y momentos bíblicos. En boca de Celestina se pone la cita de: "No sólo de pan vive el hombre, sino de toda palabra salida de la boca de Dios" (Mateo, 4.4):

[...] ¿no sabes que por la divina boca fue dicho, contra aquel infernal tentador, que no de sólo pan viviremos? [...] no el solo comer mantiene; mayormente a mi, que me suelo estar uno y dos días negociando encomiendas ajenas ayuna, salvo hacer por los buenos, morir por ellos. (IV.5).

Hay falsa piedad y entrega cristiana. Celestina no se mueve ni hace nada que no sea para sacar buen provecho. Para ella el hombre sí viviría sólo de pan.

El conocimiento de Celestina comienza con lo que dice Pármeno. La llama "puta vieja". Según él, estas dos palabras son un canto universal:

Si entre cient mugeres va y alguno dize: «Puta vieja!», sin ningún empacho luego buelve la cabeça, y responde con alegre cara. [...] Si passa por los perros, aquello suena su ladrido; si está cerca las aves, otra cosa no cantan [...] (I.5).

El citado texto puede verse como el "anticántico" de la Virgen Maria. Celestina, en lugar de la Madre Celestial, sería la madre terrenal.

Celestina ha ido a hablar con Melibea. Le contará a Calisto su visita, con un léxico de turbación que podría ser una parodia de la Anunciación que el ángel Gabriel hizo a María (Lucas, 1.29):

Cel.- [...] Abri mis entrañas, díxela mi embaxada, cómo penavas tanto por una palabra, de su boca salida en favor tuyo, para sanar un tan grand dolor. E como ella estuviesse suspensa, mirándome, espantada del nuevo mensaje, [...] (VI).

Como se ha podido comprobar, Rojas tiene conocimiento tanto del judaísmo como del cristianismo, pero el empleo que hace de ellos es distorsionado; con fines destructivos.

En La Celestina pueden encontrarse alusiones tanto a Dios como al diablo. El diablo puede aparecer formando parte de una expresión, en las exclamaciones... Sempronio, en V.2, dirá sobre Celestina: "iVálala el diablo [...]!" Lo más normal sería haber dicho "Dios" en esta expresión.

En varias ocasiones, con "diablo" se estará nombrando a Calisto. Es una forma de hablar, equivalente a nuestra actual frase "es un pobre diablo":

Pár.- [Sobre Calisto] Temblando está el diablo como azogado [...] (VI).

Hay personajes (como las brujas) que tienen una relación con el diablo. Así sucede con la madre de Pármeno y con Celestina, quien invoca al diablo en sus rituales brujeriles: 
Conjúrote, triste Plutón, señor de la profundidad infernal, emperador de la corte dañada, [...] y atormentador de las pecadoras ánimas... (III.3).

Celestina hace una alusión al infierno y a lo negativo de las religiones cristiana y judia en la referencia al ángel caído ("capitán sobervio de los condenados ángeles"). Mezcla la religión con el dios pagano Plutón. Es como si creyera en los demonios de todas las religiones.

Dios puede aparecer nombrado o simplemente aludido, como en I.10. Cuando se le menciona, puede hacerse relacionándolo con la belleza. Para Calisto Dios ha sido el creador de la belleza de Melibea: "En esto veo, Melibea, la grandeza de Dios" (I.1). Dios, creador de belleza, sólo aparecerá como eso; pero nunca como Redentor, Salvador, Mesías...

Otro aspecto con el que se relaciona a Dios es con la salud. Calisto les dice a sus criados: "Rogad a Dios por salud, que yo os galardonaré más complidamente vuestro buen servicio" (XII.7). Ya no sólo se le rogaría por motivos amorosos. Pero, como en el desarrollo de la obra se verá, Dios no les concede esa "salud", ya que morirán ejecutados.

Dios es sentido por algunos personajes como un ser malvado, al que le gusta hacer daño aunque luego dé remedios para sanarlo. Asi se lo alude Celestina a Melibea: "[...] quando el alto Dios da la llaga, tras ella embía el remedio. Mayormente que sé yo al mundo nascida una flor que de todo esto té delibre" (X.3). Celestina dice a Melibea que Dios le ha producido la herida del amor, pero para ello le da una solución: Calisto. Dios induciría al pecado, a la lujuria... Si no hubiese provocado esa herida, no seria necesario ese remedio.

Ese Dios malvado es también vengador, como menciona Areúsa: "Y de ál [otra cosa] me vengue Dios, que de Calisto Centurio me vengará" (XV.3).

Dos fuerzas ajenas a la religión ejercen su poder sobre el mundo y los hombres: el Amor y la Fortuna. El poder del amor provocará el suicidio de Melibea. Ésta, antes de arrojarse desde la torre, dirá: "[...] presos mis sentidos de tan poderoso amor del muerto cavallero, que priva al que tengo con los vivos padres" (XX.3).

Para Melibea, Calisto no ha muerto por haberlo así dispuesto Dios, sino por haber sido ordenado por la Fortuna:

[...] a la buelta de su venida, como de la Fortuna mudable estoviese dispuesto y ordenado, según su desordenada costumbre, como las paredes eran altas, [...] y él baxava pressuroso [...], puso el pie en vazio y cayó (XX.4).

En la religión cristiana, o en la judia, la única fuerza superior posible es la de Dios. Las fuerzas anteriores no serian admitidas.

A continuación estudiaremos si los personajes de La Celestina creen en alguna religión, y de qué forma lo hacen, a través de: Celestina, Melibea y Calisto.

Menéndez Pelayo dice que los personajes hablan como cristianos pero proceden como gentiles; sin noción de pecado ni de remordimiento.

Para Calisto Melibea es su Dios: "[...] Melibea es mi dios, Melibea es mi vida [...]" (XI.2). Esto es una "herejia amorosa". Dios es vida. Melibea es vida, Melibea es Dios. Calisto continuará: "¿Yo? Melibeo soy y a Melibea adoro y en Melibea creo y a Melibea amo" (I.2). La religión de Calisto es la del amor.

Melibea, como Dios, puede salvar o condenar al hombre: 
Cal.- [...] la mesma boca desta que tiene las llaves de mi perdición y gloria [...] (XII.3).

Melibea también se considera Dios a si misma: "Que yo soy dichosa si de mi palabra hay necessidad para salud de algún cristiano. Porque hazer beneficio es semejar a Dios [...]" (IV.5). Pero ella no hará ningún beneficio a Calisto pues lo llevará a la muerte.

Melibea, para Calisto, también es similar a un ángel. Cuando se ve cara a cara con ella exclama: “¡O angélica ymagen!” (XIV.3).

Otro personaje que en alguna ocasión aparece como una divinidad es Celestina. Calisto ve en ella la solución de su problema amoroso y, cuando llega a la casa a verle, la dirá: “¡O gloriosa esperança de mi desseado fin! ¡ $O$ fin de mi deleytosa esperança! ¡O salud de mi passion, reparo de mi tormento, regeneración mía, vivificación de mi vida, resurrección de mi muerte!" (I.9). Celestina sería como un dios. El léxico religioso está ligado a su figura. De ella le puede llegar a Calisto la salvación o la condenación (si le dice que Melibea le ha rechazado).

Pero Celestina guarda una estrecha relación con el diablo. Éste siempre va con ella. Pensará: "(Por aquí anda el diablo aparejando oportunidad, arreciando el mal a la otra. ¡Ea, buen amigo, tener recio! [...])" (IV.4). En el pensamiento de Celestina se comprueba la verdad de sus intenciones. El diablo es para ella un buen amigo. Lo invocará en sus prácticas de brujeria:

Yo, Celestina, tu más conocida cliéntula, te conjuro por la virtud y fuerça destas vermejas letras, [...], vengas sin tardança a obedescer mi voluntad [...]. Si no lo hazes con presto movimiento, ternásme por capital enemiga; heriré con luz tus cárceres tristes y escuras [...] (III.3).

Si las brujas están al servicio del demonio, están al "des-servicio" de Dios. Pero Celestina parece ser incluso más malvada y poderosa que el propio diablo. Podría ser el mismísimo diablo. Ello explicaría que él siempre anduviera con ella.

Rojas introduce una ironía con el nombre de la alcahueta. "Celestina" se relaciona con celeste y con cielo; pero el personaje no tiene nada que ver con lo celestial. Evoca el cielo un ser monstruoso de la sociedad y de la moral.

Calisto en alguna ocasión aparece como un dios para Melibea: "En pensar en él me alegro, en verlo me gozo, en oýrlo me glorifico. Haga y ordene de mí a su voluntad" (XVI.2). La frase final recuerda a la de Jesucristo, referida a Dios: "Hágase tu voluntad y no la mía".

Sempronio pensará de Calisto: “[...] no basta loco, sino ereje”, y tendrá con él el conocido diálogo en el que Calisto se reconoce "melibeo" (I.2). Calisto no es cristiano.

Melibea no parece creer en Dios y lo demuestra al no tener ningún reparo en suicidarse. Celestina es avariciosa y se dedica a ir haciendo el mal entre la gente. Ni ellas ni Calisto pueden ser considerados personajes cristianos.

En la obra se hace una utilización del lenguaje en la que la religión y Dios están presentes en las expresiones coloquiales. Celestina dice el siguiente refrán: "Da Dios havas a quien no tiene quixadas" (I.10).

En las despedidas todos se mandan unos a otros con Dios, pero Dios no está con ninguno. Es una forma de hablar; una fórmula hecha y repetida. Un ejemplo es:

Cel.- Quede Dios contigo.

Cal.- Y Él te me guarde. (I.12).

En las exclamaciones y en los momentos de máxima tensión es muy frecuente el uso de Dios: Calisto está expectante por saber lo que Melibea le ha dicho a Celestina: 
Cal.- ¡O Dios mio, que alto don! [...] ¡O por Dios, toma toda esta casa y quanto en ella hay y dimelo [...]!

Cal.- Pero dime, par Dios, ¿passó mas? (VI).

Dios aparece en un momento de enorme tensión. Es ponderación del discurso. Cuando los criados van a matar a Celestina, Elicia exclama: "¡Mete, por Dios, el espada! ¡Tenle, Pármeno, tenle, no la mate esse desvariado!" (XII.10). "Dios" aparece como viveza expresiva, ante exclamaciones de espanto... Así expresará Pleberio su nerviosismo, en XX.1, al ver a su hija tan dolorida.

Como en apartados anteriores, la aparición de Dios es utilizada para otros fines; en este caso meramente expresivos.

Por último vamos a analizar el Prólogo, las piezas finales y el Monólogo de Pleberio.

La Celestina incluye dos prólogos; que no tienen nada que ver entre sí. En la carta a un su amigo, el autor considera que el problema de Castilla es la cantidad de jóvenes enamorados que hay. Por ello escribe el libro. Pero éste es muy complejo: está lleno de filosofias, críticas sociales, religiosas... En esta carta todo es ambiguo y conscientemente confuso. A pesar de ello, Rojas dice que su libro es un aviso a los enamorados. En los poemas de El autor escusándose de su yerro en esta obra que escrivió, contra si arguye y compara nos indica que en ella muestra a los amantes "salir de cativo", pero ¿cómo?: ¿suicidándose?

Jesucristo no es mencionado ninguna vez en la obra. Sólo es aludido en los poemas iniciales y finales del libro. Lo más probable es que esté tratando de disimular y de envolver sus intenciones reales, presentando y conciuyendo su obra como cristiana.

Lo siguiente en aparecer es el Prólogo. Comienza: "Todas las cosas ser criadas a manera de contienda o batalla". Pertenece a Heráclito y expresa un materialismo mecanicista. Somos víctimas de un mecanismo cósmico. La filosofia materialista no está de acuerdo con las ideas cristianas, pero es justo de esta frase de Heráclito de donde sale La Celestina. Petrarca aparecerá en el Prólogo corroborando la sentencia: "Sin lid y ofensión ninguna cosa engendró la Natura, madre de todo". Entonces, ¿dónde está Dios? Petrarca es la mayor fuente de La Celestina, a partir de la cual se construirá otra cosa.

Todo da testimonio de la lucha. El ejemplo de cómo se reproduce la víbora sirve para entender todo el libro:

La bivora, reptilia o serpiente enconada, al tiempo de concebir, por la boca de la hembra metida la cabeça del macho y ella con el gran dulçor apriétale tanto que le mata y, quedando preñada, el primer hijo rompe las yjares de la madre, por do todos salen y ella muerta queda, él quasi como vengador de la paterna muerte.

Si el mundo es asi, el mundo es horrible. Calisto y Melibea mueren; él primero y ella después. El amor produce la muerte. Todo lo dicho es sujeto a los hombres: tienen guerra, enemistad, envidia, odio, cambio y lucha continua. Porque en todo está presente la lucha, el autor dirá:

no quiero maravillarme si esta presente obra ha seydo instrumento de lid o contienda a sus lectores para ponerlos en differencias, dando cada uno sentencia sobre ella a sabor de su voluntad. Unos dezian que era prolixa, otros breve, otros agradable, otros escura; de manera que cortarla a medida de tantas y tan differentes condiciones a sólo Dios pertenesce.

Cuando aparece Dios se ve reducido a entidad hipotética y omnisciente por excelencia, y no como ser supremo creador y ordenador del universo. Que la obra le parezca a cada uno una cosa sólo puede hacerlo Dios. A pesar de ser nombrado, en este prólogo no hay mención alguna a la 
vida espiritual o al sentimiento religioso... A mi parecer, en este Prólogo se expresa la verdadera ideología del autor. Dentro de las piezas finales, los poemas de Concluye el autor, aplicando la obra al propósito por que la acabó contrastarían con esa verdadera intención de la obra, a base de grandes convencionalismos y tópicos moralistas. Este epilogo final está escrito en loor de Cristo, al que nosotros sólo hemos de amar. Es una estrofa ortodoxa cristiana pero, a pesar de ello, no se menciona el nombre de Cristo; sólo se le alude. No olvidemos, de nuevo, a la Inquisición y que parte de la familia de Rojas había sido aniquilada por ella. Éste puede ser el motivo del ataque a los judios en la estrofa ("Los falsos judios su haz escupieron"). Ésta choca con todo lo leido en lo que es la obra en sí. Rojas no la incluye en ella hasta 1507, pero las ediciones anteriores aparecieron anónimas. Por algo sería. La razón parece ser el miedo a la Inquisición, por haber escrito un libro (a pesar de las posibles apariencias) en absoluto cristiano. Fue lo que le llevó a escribir la carta inicial y este epilogo. Le servirian de marco para burlar a la Inquisición y que ésta lo diera de paso. En esta pieza con la que concluye el autor dice expresar su intención en: "[...] zeloso de limpio bivir,/ zeloso de amar, tener y servir / al alto Señor y Dios soberano". A la Inquisición le parecería una obra moral, que serviria de ejemplificación de lo que un buen cristiano no ha de hacer. Pero a cada paso el texto nos deja ver que esto no es asi. Junto con el Prólogo filosófico, corroboración de ello es el Monólogo final.

El Monólogo de Pleberio constituye el acto XXI, y está en relación con los prólogos iniciales. En él está la verdadera ideología de su autor. Asi lo cree S. Gilman. (En F. Rico, 1979: 522-523).

Pleberio, tras suicidarse su hija, comienza su monólogo. Lo hace con un refrán antidramático: “¡Nuestro gozo en el pozo!”. Continúa: “Nuestro bien todo es perdido! ¡No queramos más vivir!” En él no está presente la creencia en el perdón de Dios (hacia su hija), la resignación cristiana, la aceptación de la muerte... A Pleberio no le preocupa y duele tanto que haya muerto su hija, como la causa por la que ha muerto (amor) y la soledad y el desconsuelo que a él le queda. Cree que se ha cambiado el orden natural de las cosas. Lo normal es que los padres mueran antes que los hijos. El mundo es un caos.

El egoísmo de Pleberio se manifiesta al quejarse de haberse quedado sin heredera: " $\mathrm{O}$ duro coraçon de padre!, ¿cómo no te quiebras de dolor, que ya quedas sin tu amada heredera?"

Hace un ataque contra el mundo, al que da diversas definiciones:

- "laberinto de errores". Los laberintos no se construyen solos. Julio Rodríguez Puértolas (1976: 166) cree que el responsable es el hombre. Yo, más me inclinaría a pensar en Dios como el creador de ese laberinto de errores. Podría aludir a la deficiencia con la que Dios ha creado las cosas, o a una posible maldad de ese Dios malvado àl que se aludía en la obra para con el hombre.

- “desierto espantable". Esta idea viene de la Biblia y está presente en la filosofía pesimista judía.

- "morada de fieras". Aparece en la filosofia pesimista.

- "juego de hombres que andan en corro". Este juego puede durar eternamente. Es un círculo que gira, y sólo puede terminar con la muerte. La muerte es la paralización de ese círculo y la salida del laberinto.

Pleberio le preguntará al mundo: “¿A dó pones mi hija?” No sabria dónde va tras la muerte.

Ahora realiza un ataque contra el amor. Ha habido gente que lo ha llamado "dios", pero cree que es una equivocación: "Dios te llamaron otros, no sé con qué error de su sentido traýdos. Cata que Dios mata los que crió; tú matas los que te siguen”. El amor sería más poderoso que Dios; que 
la voluntad de Éste. Aunque cree que los que le han denominado "dios" se han equivocado, no es así. No hay diferencias entre ellos: los dos son dioses brutales. Pero thay dos dioses de verdad? Una definición de Dios es que "Dios es Amor". Quizá Pleberio (como Rojas) identifique a ambos en uno. M. Marciales (1985:266) defiende que en "Cata que Dios mata los que crió" habría un "no": Dios no mata los que crió. Esto, desde el texto, no puede justificarse de ninguna forma. Pleberio podría estar pensando en el Dios vengador del Éxodo 20.5, que toma en los hijos la venganza de los padres. (Véase lo que sobre este tema escribe S. Gilman, en Francisco Rico, 1979: 524).

Pleberio continúa dirigiéndose al amor y le dice:

Tu fuego es de ardiente rayo, que jamás haze señal do llega. La leña que gasta tu llama son almas y vidas de humanas criaturas, las quales son tantas que de quien començar pueda apenas me ocurre. No sólo de cristianos, mas de gentiles y judios, y todo en pago de buenos servicios.

Tanto los cristianos como los judíos son quemados en las llamas del amor. Ambos están al mismo nivel. Pero la leña a la que se hace referencia puede ser la de las hogueras inquisitoriales. El fuego del amor -y de la Inquisición- funciona para las diversas religiones.

Finalmente, Pleberio reprocha a su hija haberle dejado triste y solo: "¿Por qué me dexaste triste y solo in hac lachrimarum valle?" Acaba con una frase latina de una oración cristiana medieval a la Virgen María. De ella, lo único que saca Rojas es que el mundo es un valle de lágrimas. Nada en el texto autoriza a un final esperanzador. Cabria pensar en otra interpretación, pues la misma expresión, también en latín y como cierre de la obra, aparece en las Coplas de Mingo Revulgo. Estas coplas constituyen una sátira.

En resumen, el monólogo plantea tremendos problemas desde el punto de vista religioso: ausencia de valores cristianos, existencia de dos dioses (y ambos matan), concepción negativa del mundo..., angustia y desesperanza impropias del cristianismo...

La conclusión que podemos sacar dejándonos llevar por el propio texto es que la religión sólo hace presencia en él para ser destruida. Se ha producido la crisis del Feudalismo, y con ella un cambio a todos los niveles. En La Celestina se produce una destrucción en todos los ámbitos: desde los tópicos del amor cortés, las normas sociales, el ideal de amistad, la familia... hasta la religión. Rojas hace un uso de la Literatura con fines subversivos, destructivos. La destrucción no es sólo del texto literario, sino de lo que está más allá de éste: la sociedad que lo ha producido y la cultura en la que está asentado. María Rosa Lida piensa que para Rojas, un converso, tener que vivir en la sociedad en la que vivía tenía que ser una continua pesadilla. Supone que "Al observar esa sociedad en la que no estaba integrado, subraya de forma sarcástica sus contradicciones, sus prejuicios, sus convenciones". Tiene "una visión desoladora del mundo". (En Cardiel Sanz, 1981: 157). Efectivamente, uno de los aspectos atacados en la obra es la sociedad. También es cierto que su visión sea desoladora, pues no hay abierto ningún resquicio hacia la esperanza.

Américo Castro defiende "el ánimo subversivo de Rojas" y opina que "La finalidad de esta tragicomedia no fue moralizar ni criticar primordialmente el orden social o religioso. Lo que de esto haya es reflejo secundario de otros propósitos más hondos: la perversión y el trastorno de las jerarquías de valoración vigentes, de los ideales poéticos y caballerescos”. (En Cardiel Sanz, 1981: 157158) Las ideas de Castro son correctas, pues todo lo que aparece en el libro es para ser destruido.

Quizá la presencia de la Inquisición fue lo que determinó a Rojas a componer las octavas finales y el prólogo inicial; que en nada tienen que ver con la carta a un su amigo. Trató de hacer pasar su obra por moralista, y lo logró. 


\section{Bibliografia}

Edición utilizada: Rojas, Fernando de: La Celestina. Ed. Julio Rodríguez Puértolas. Madrid, Akal, 1996.

BaLDWIN, Spurgeon: «Pecado y retribución en La Celestina», Dicenda, 6, 1987, 71-81.

CARDIEL SANZ, Estrella: «La cuestión judia en La Celestina», en Antonio Viudas Camarasa, ed., Actas de las Jornadas de Estudios Sefardies, Cáceres, Universidad de Extremadura, 1981, 151-159.

Gilman, Stephen: «La voz de Fernando de Rojas en el monólogo de Pleberio», en Francisco Rico: Historia y Crítica de la Literatura Española, 1: Edad Media, Barcelona, Crítica, 1979.

GiLman, Stephen: "La Celestina”: arte y estructura, Madrid, Taurus, 1982.

GreEN, Otis H.: España y la tradición occidental, Madrid, Gredos, 1969, I, 139-148.

Maravall, José Antonio: El mundo social de "La Celestina", Madrid, Gredos, 1964.

MARTINEZ-MILlER, Orlando: La ética judia y "La Celestina» como alegoria, Universidad de Miami, 1978.

MENÉndez Pelayo, M.: Origenes de la novela, III, Madrid, Bailly // Bailliére, 1910.

Morón Arroyo, Ciriaco: Sentido y forma de “La Celestina”, Madrid, Cátedra, 1984.

RIPOLl, Carlos: "La Celestina" a través del decálogo y otras notas sobre la literatura de la Edad de Oro, Nueva York, Las Américas, 1969.

Rodríguez Pú́rtolas, Julio: "La Celestina o la negación de la negación», en Literatura, Historia, Alienación, Barcelona, Labor, 147-171, 1976.

RoJAS, Fernando de: Celestina. Tragicomedia de Calisto y Melibea. Introducción y edición crítica de Miguel Marciales, II: 266, Illinois, Crítica, 1985.

\section{RELIGIOZNI VIDIK V DELU "LA CELESTINA”}

"La Celestina", glede vprašanja o religioznem, razdvaja avtorje: nekateri ne najdejo v delu niti sledi religioznega (A. Castro, J. R. Puértola...), drugi skušajo besedilu pripisati moralni in verski namen, nekateri vidijo krščanske elemente v "La Celestini" (M. Pelayo, G. Correa...), drugi spet judovske (R. de Maeztu, S. Poncela...). Avtorica najprej podkrepi to razdvojenost s citati tistih delov besedila, ki:

a) združujejo poglede vseh treh religij Iberskega polotoka tedanjega časa (krščanske, judovske in muslimanske),

b) kažejo na sledi (samo) judovstva,

c) omogočajo ateistično branje in razumevanje.

$\mathrm{V}$ jedru članka avtorica dokazuje naslednje:

a) Navzven, navidez je Bog prisoten: gre za prisotnost sprevržene vere, lažne vere, kjer se svetopisemska besedila uporabljajo perverzno, kot pretveza za utemeljevanje zlih dejanj; gre za parodijo vere, za satiro; Boga (tudi hudiča) se kliče, se nanj obrača, prosi se ga za materialne dobrine, za uspeh v ljubezni in v zlih dejanjih, za zdravje... ime Boga se pojavlja v vzklikih, pozdravih... takšnega kulturno-krščanskega občutenja je "La Celestina" polna, ne pa tudi krščanstva.

b) V resnici, v dejanjih oseb (umori, samomori, maščevanja, čarovnišstvo...) pa je Bog odsoten, ga sploh ni: - svet $\mathrm{v}$ resnici vodita dve razdiralni sili, ki sta religiji (krščanski in judovski) tuji, in sicer: moč ljubezni, ki pahne npr. Melibeo v samomor, ter moč usode, ki določa življenje (ne usmerja ga Bog);

- Celestina, Melibea in Calisto ne verjamejo v nobeno religijo (Calistu je bog Melibea, Melibei je bog Calisto in ona sama, Celestina pa - sama skoraj utelešeni hudič - se tudi nekaterim včasih dozdeva božja);

- v monologu Pleberia ob smrti hčere lahko razberemo popolno odstotnost krščanskih vrednot, prepričanje v obstoj dveh bogov (in oba ubijata), negativističen koncept sveta, itd.

Avtorica zaključuje $\mathrm{z}$ ugotovitvijo, da je prišlo v času razpada fevdalne družbe do sprememb na vseh področjih (družbene norme, hierarhija vrednot in idealov, npr. prijateljstva, ljubezni, družine, celo vere), kar se odraža v delu "La Celestina", kjer se vse, kar se v besedilu pojavi (religija, družba, itd.), pojavi zato, da se raztrga, uniči. Ne gre samo za destrukcijo literarnega besedila ampak za destrukcijo tistega, kar ga presega: družbe, ki ga je ustvarila, in kulture, v kateri je nastal. Vse torej, kar se v besedilu znajde, je razvrednoteno, uničeno. Čeprav je Rojasu s spremnini in zaključnimi besedami h knjigi uspelo predstaviti delo kot moralistično (po vsej verjetnosti zaradi inkvizicije). 